\title{
SiNFONIA A MUITAS MÃOS: ESBOÇO ETNOGRÁFICO DE UM PROJETO CIENTÍFICO E AS VICISSITUDES DAS POLÍTICAS DE AVALIAÇÃO
}

\section{Lady Selma Ferreira Albernaz ${ }^{1}$}

\begin{abstract}
Resumo
Este artigo descreve o processo de elaboração de um projeto para submissão ao Programa Nacional de Cooperação Acadêmica (PROCAD) da Coordenação de Aperfeiçoamento de Pessoal de Nível Superior (Capes). Sua finalidade é discutir se os resultados das políticas interinstitucionais fortalecem ou não as instituições periféricas, conforme preconizado nos seus objetivos. Tal discussão passa pela análise das atuais políticas de avaliação tanto dos Programas de Pós-Graduação como do corpo docente a estes vinculados, cujo efeito parece ser a substituição do princípio da cooperação acadêmica pelo da competição entre pares. 0 texto originou-se da participação no Seminário Interinstitucional Ciência e Saberes na Amazônia (UFPE, 2005), na mesa redonda Políticas Interinstitucionais de Pesquisa e Formação.
\end{abstract}

Palavras-chave: Política interinstitucional. Avaliação universitária. Pósgraduação.

\footnotetext{
${ }^{1}$ Professora Adjunto 1, Departamento de Ciências Sociais, Programa de Pós-graduação em Antropologia-UFPE. Coordenadora dos Cursos de Graduação em Ciências Sociais - Bacharelado e Licenciatura da mesma instituição.
} 


\title{
Symphony by Many Hands: Ethnographic SKetch for a Scientific Project and the Vicissitudes of Evaluation Policies
}

\begin{abstract}
This article describes the process of elaborating a project for submission to the National Programme of Academic Cooperation (PROCAD) of the Commission for the Training of Personnel for Higher Education (Capes). Its aim is to discuss whether the results of inter-institutional policies strengthen peripheral institutions, as its formal objectives state. This discussion encompasses the analysis of the current evaluation policies of both graduate programs and the academic faculty attached to them. These policies seem to replace principles of academic cooperation with competition between colleagues. The text was based on the author's participation in the Inter-Institutional Seminar on Science and Knowledges in Amazônia (UFPE, Recife, out/2005) and more specifically on the discussions of the round-table on Inter-Institutional Policies for Research and Training.
\end{abstract}

Keywords: Inter-institutional policies. Academic evaluation. Graduate.

E ste artigo descreve o processo de elaboração de um projeto submetido à apreciação do Programa Nacional de Cooperação Acadêmica (PROCAD) da Coordenação de Aperfeiçoamento de Pessoal de Nível Superior (Capes). Sua finalidade é discutir se os resultados das políticas interinstitucionais (como é o caso do PROCAD) fortalecem ou não as instituições periféricas conforme consta nos seus objetivos. Desdobra-se para uma análise das políticas atuais de avaliação da produção docente e seus rebatimentos na pontuação dos Programas Pós-graduação (PPG's), que parecem substituir o princípio da cooperação pelo da competiçã̃ ${ }^{2}$.

Os pontos abordados são as políticas interinstitucionais da Capes e 0 modelo de aliança implícito na sua constituição, desenvolvidos à luz do relato da

\footnotetext{
${ }^{2}$ Este artigo é uma nova versão ampliada de Etnografia Sucinta de um Projeto Científico ou das Lições de Política Inter-Institucional. (ALBERNAZ, L. 2008). Agradeço ao professor Renato Athias o convite para participar do evento que deu origem ao mesmo. Nesta segunda versão agradeço as sugestões das colegas Simone Wolff e Martha Ramírez-Gálvez, que permitiram levantar novos argumentos, aprofundando as reflexões aqui expostas. No último momento, sou grata a Simone Frangella por traduzir o resumo.
} 
experiência da elaboração de um projeto para o PROCAD, realizado a muitas mãos, algo que poucas vezes compartilhamos entre nós. Desdobra-se para refletir sobre políticas para educação superior no país e suas (des)conexões, no que se refere à percepção dos avaliadores da Capes sobre o que deve ou não ser pontuado como produção acadêmica. Faço um esforço de análise sobre os critérios que balizam 0 que seja produtividade e suas conseqüências para a formação e a manutenção de departamentos dentro das universidades.

0 texto está dividido em três partes. Na primeira, situo como esta reflexão foi suscitada. Na segunda, faço efetivamente a etnografia do processo de montagem do projeto. E na última parte, exponho os argumentos sobre as políticas da Capes, tanto aquelas relativas às alianças interinstitucionais e seus possíveis resultados, bem como sobre as lacunas relativas à contagem da produção docente nas avaliações dos PPG's, ou seja, das produções visíveis e invisíveis nessas contagens.

\section{Contexto}

Este artigo resulta da participação na Mesa Redonda "Políticas Interinstitucionais de Pesquisa e Formação", realizada no Seminário Interinstitucional Ciência e Saberes na Amazônia (UFPE - Recife-PE, outubro de 2005). 0 evento encerrava as atividades do "Projeto Integrado de Pesquisas e Cooperação Interinstitucional", financiado pela Capes e celebrado entre 0 Programa de Pós-graduação em Sociedade e Cultura na Amazônia (UFAM) e o Programa de Pós-graduação em Antropologia (UFPE) (NORONHA e ATHIAS, 2008). Apesar de não ter feito parte da equipe do Projeto $0^{3}$, fui convidada a contribuir com as reflexões sobre política interinstitucional, tendo em vista a experiência que tive como integrante de uma equipe que, naquele ano, havia submetido um Projeto dessa natureza: o PROCAD.

Inicialmente pensei em recusar o convite, por achar que não traria contribuições adequadas aos objetivos do seminário, que avaliava um projeto do qual eu não participara. Entretanto, tomando a devida distância dos acontecimentos, considero hoje que a decisão de aceitar o convite foi acertada. As reflexões que fiz sobre as políticas da Capes, a partir do PROCAD, permitiram-me compreender melhor como outras atividades, nas quais me envolvi posteriormente,

\footnotetext{
${ }^{3}$ No período de sua implementação eu não integrava o Programa de Pós-Graduação em Antropologia (PPGA-UFPE) por estar realizando o doutorado.
} 
não são consideradas pontuáveis por esta instituição, tendo em vista as diretrizes de produtividade que orientam o processo de avaliação do ensino superior, em particular dos PPG's .

$\mathrm{Na}$ mesa em que participei mais dois trabalhos foram apresentados. Um deles tratava do desafio de inserir as temáticas de humanidades nos editais voltados para o desenvolvimento agrário (ANDRADE, 2008). Nesse sentido, como estabelecer relações interinstitucionais entre áreas de conhecimento vistas como dispares e incomunicáveis? Mesmo que as tecnologias a serem desenvolvidas pelas ciências agrárias tivessem como alvo populações estudadas pelas humanidades, cujos resultados apontam as especificidades desses grupos e, portanto, a possibilidade delas discordarem das inovações propostas que poderiam desrespeitar seu modo de ver 0 mundo e organizar o trabalho, ainda assim as humanidades não eram ouvidas. 0 segundo trabalho (CAVALCANTI, 2008), debruçou-se sobre 0 desenvolvimento das políticas de fomento, salientando seu crescimento positivo ao longo do tempo.

Estes trabalhos mostravam algumas possibilidades de refletir sobre políticas interinstitucionais incentivadas pelos órgãos de fomento a pesquisa. Considerando as diferenças geográficas e sócio-culturais entre as regiões onde as instituições se situam, é possível reunir ou não a Amazônia e o Nordeste num mesmo projeto? Passando pelo tipo de instituições que podem ser agrupadas, é possível reunir num mesmo projeto Instituições de Ensino Superior (IES), movimentos sociais e/ou organizações não governamentais, posto que produzem saberes distintos? Até sobre a viabilidade de transformar pesquisa acadêmica em projetos de desenvolvimento, é possível traduzir os conhecimentos das humanidades em políticas de desenvolvimento, ou isto só é cabível para as outras áreas do saber?

\footnotetext{
${ }^{4} 0$ debate sobre este tema tem se intensificado, havendo um movimento docente que contesta os parâmetros atuais da Capes e do CNPq e propõe novos critérios de avaliação (Cf. Manifesto contra o CNPq publicado em 29 de Dezembro de 2008. Disponível em: http://www.estadao.com.br/ estadaodehoje/20081229/not_imp300080,0.php. 0 debate circula em jornais (VIEIRA, 2009) e em alguns artigos, por exemplo, Rodrigues (2007). Um texto seminal é o de Fonseca (1998), no qual ela constata que os critérios quantitativos, na época recém adotados pela Capes, davam resultados semelhantes nas pontuações dos programas se eles fossem avaliados pelos critérios qualitativos anteriores. A autora concluía apontando os riscos do "produtivismo", embutidos no modelo de avaliação que estava sendo testado, mas colocando-se na espera das suas conseqüências. Em 2008 foi lançada a coletânea que reuniu os textos do Seminário que deu origem a este trabalho, no qual mais dois tratam de avaliação: Andrade (2008), mais cético em relação aos critérios de avaliação e Cavalcanti (2008), mais otimista.
} 
0 meu trabalho aproximava-se mais do processo mesmo de constituição de uma equipe interinstitucional e, simultaneamente, tratava da política acadêmica que sustenta a (re)união de pesquisadores, com maior ou menor costume de trabalhar juntos, perpassada pela questão de como montar alianças entre as instituições. Dessa forma, ao etnografá-lo, por me sentir mais a vontade com esta ferramenta metodológica da antropologia, pude me aproximar da compreensão da lógica interna que rege a elaboração de um projeto científico para fins de submissão em Edital, reflexão sobre a qual poucas vezes temos oportunidade de nos deter, tanto do ponto de vista da divisão do trabalho para que o projeto venha a lume, como sobre as alianças que instituímos para montá-lo. Com este enfoque surgiu, ainda, outra possibilidade de tratar este tipo de política de fomento: até que ponto as políticas interinstitucionais da Capes beneficiam as instituições consideradas periféricas (seu suposto objetivo), ou têm o efeito contrário de fortalecer os já consolidados centros de excelência? No seu desdobramento foi possível incorporar outras questões e argumentos, dando relevo também aos processos de pontuação da produção docente e como isto rebate na avaliação dos PPG's. Tendo em vista minhas atividades atuais, por um lado, como coordenadora do Curso de Graduação em Ciências Sociais (Bacharelado e Licenciatura), por outro lado, as ações de extensão em andamento, tornaram possível pensar como as pontuações da Capes desconsideram as políticas do MEC, especialmente 0 envolvimento das IES públicas na melhoria da educação básica.

Dessa maneira, espero que o tom etnográfico aqui empregado, configurese como uma boa ferramenta, pois nada melhor do que um olhar de dentro para desvelar os percalços próprios à montagem de um projeto de cooperação; especialmente pela perplexidade diante da justificativa da Capes para não financiá-lo.

\section{ETNOGRAFANdo o PROCAD - UMA SINFONIA A MUITAS MÃOS 5}

Vale a pena iniciar expondo como me sinto diante dos trâmites burocráticos necessários a um Edital relativo à submissão de um projeto acadêmico: paralisada e obnubilada. Particularmente este último termo arcaico, que significa perder a consciência ou se obscurecer, expressa bem minhas sensações diante de um edital

\footnotetext{
${ }^{5}$ A descrição está apresentada em linguagem coloquial propositalmente, pois não quis perder o tom de relato oral para acentuar os percalços próprios de uma experiência.
} 
e seus vários formulários, regras de preenchimento e passos a serem dados para chegar a um portal, quase sempre impossível de abrir. Bem, foi numa empreitada desse tipo que me lancei quando me ofereci para integrar a equipe do PPGA-UFPE que montaria o citado/referido projeto para submissão ao edital PROCAD/2005 da Capes.

Relembrando como surgiu esta tarefa para mim. Em uma reunião do Colegiado do PPGA-UFPE, o então coordenador, Prof. Renato Athias, anunciou que a CAPES havia aberto o Edital do PROCAD/2005. Ele sugeria aos colegas que tomassem a iniciativa de concorrer ao Edital, o que traria muitos benefícios ao nosso Programa, sobretudo pela oportunidade de articulação e intercâmbio com outras instituições consolidadas. Considerando que seria uma boa oportunidade para retribuir aos colegas pelo fato de ter ficado afastada para realização do doutorado, além de começar efetivamente a contribuir com o PPGA, na condição de recém-doutora, ofereci minha colaboração. A esta oferta seguiu-se um silêncio enigmático que, como neófita, não compreendi. Vejo hoje que por ser nova na pós-graduação os colegas devem ter pensado que eu não teria trânsito suficiente entre os pares para conseguir compor alianças e, por sua vez, poderia não estar preparada ainda para elaboração de projetos deste porte. De certa forma eles tinham razão, não conhecia pessoas estratégicas para compor as alianças, por um lado e, por outro, a tarefa não foi fácil! Em alguns momentos me senti com forças aquém às requeridas pelo processo.

Esclarecendo, o que é o PROCAD? Segundo as definições da CAPES, visa a formação de recursos humanos de alto nível, nas diversas áreas do conhecimento, vinculada a projetos conjuntos de pesquisa de média duração. Simultaneamente, busca intensificar o intercâmbio científico no país, por intermédio do envolvimento de equipes acadêmicas de diversas instituições de ensino superior e de pesquisa brasileiras, criando condições para a elevação geral da qualidade do ensino superior e da pós-graduação $0^{6}$.

o Programa se constitui, junto com a promoção de Mestrados e Doutorados Interinstitucionais, num tipo de ação voltada para estimular a formação acadêmica e os projetos de pesquisa que reúnam distintas instituições, com o intuito de ampliar a pós-graduação no Brasil, por meio de uma cooperação que possibilite, aos cursos consolidados, contribuir para a implantação de novos programas ou fortalecimento dos existentes. Dessa forma todos saem lucrando: os professores

${ }^{6}$ http://www.capes.gov.br/capes/portal/conteudo/10/PROCAD.htm.Visitado em 06/06/2006. 
localizados no interior do país, ao serem estimulados a desenvolver pesquisa e simultaneamente aumentar suas titulações; o corpo discente, pela oportunidade de continuar sua formação, integrando-se em projetos científicos, participando de eventos e, não menos importante, pela possibilidade de contar com mais bolsas e programas do tipo "sanduíche" nas instituições consolidadas. Por sua vez, regiões com pouca tradição acadêmica tornam-se aptas para sedimentar suas universidades com a criação e fortalecimento de novos programas que vão além da graduação. Isto posto, voltemos à etnografia anunciada.

Tendo chegado à minha Ilha Trobriand sem o perceber e, pior ainda, sem um manual de etnografia, enchi-me de ânimo para trabalhar na montagem do projeto para o PROCAD. Note-se que naquele momento eu não tinha uma idéia muito clara do que seria o referido programa e, muito menos, do que seria necessário fazer. Continuei sem saber, posto que antes de começar o projeto, ou ter tempo de me angustiar em decifrar o enigma do Edital, surgiram dificuldades mais urgentes que deram cabo do importante, passemos a elas.

Assim, a primeira barreira que se anunciou foi: com quem comporemos? A segunda, talvez mais difícil, situada no nível de análise de conjuntura e das conjecturas, que não deixava nada a dever a partidos e sindicatos, foi: como os "Outros" do Nordeste estariam se aliando aos do SUDESTE? Sudeste com todas as letras em maiúscula, apenas ELE é considerado nação. Foi difícil, no mínimo difícil... Afinal, na minha apreciação, o problema da articulação e composição das outras IES do Nordeste com as do Sudeste não nos afetaria! Para mim tínhamos mérito, capacidade de articulação e certo charme para convencer - no mínimo o mar azul de Pernambuco (um ou outro tubarão mutila, mas nem sempre mata...). Aí foi um tal de: fulano já se compôs com sicrano e eles têm muito mais chances do que nós porque... (seguia-se uma enxurrada de argumentos paralisantes, todos contra o nosso PPGA); pior ainda: beltrano tem aliados fortes na Capes, além de ter juntado ao Sul (região geopolítica), portanto, nós não vamos conseguir...

Certo pandemônio marcou as primeiras reuniões, telefonemas e conversas de corredor. Um não acabar mais de conjeturas sobre as impossibilidades nossas: no plano das alianças, nenhuma se afigurava possível; no plano político, estaríamos liquidados!

\footnotetext{
${ }^{7}$ Os antropólogos às vezes usam o termo como metáfora para designar a chegada ao campo e/ ou encontro com o grupo social que será investigado, em referência ao trabalho pioneiro de Malinowski nesta Ilha.
} 
Bem, é preciso dizer que as tintas aqui são carregadas. A memória, além de resultar de uma disputa entre o que se lembra e o que se esquece, também recobre de interpretação os fatos ocorridos. Assim, o que quero dizer, é que aprendi que na montagem de um projeto desse tipo a primeira questão a ser resolvida é a composição da equipe interinstitucional que vai efetivá-lo. Se o Edital deixa claro o critério objetivo para as alianças, como por exemplo, as pontuações que os PPGs devem ter, ele não esclarece as sutilezas da política universitária, que envolvem questões além desses mesmos critérios objetivos de pontuação.

Não se pode esquecer que, se as análises conjunturais que alguns colegas faziam pareciam alarmantes, há impedimentos variados para compor uma equipe desse tipo. Há desconfianças, às vezes justificadas, outras nem tanto, de que a formação dos pesquisadores do Norte e Nordeste não seja sólida o suficiente para merecer investimentos. Há alianças preferenciais com IES periféricas para onde foram egressos dos programas do centro. Há relações estratégicas dentro das agências de fomento que podem tornar alguns proponentes mais meritórios... Enfim, compor uma equipe de um projeto interinstitucional é difícil, seja porque internamente os periféricos se avaliam com tintas muito negativas, seja porque são assim avaliados pelos tais programas consolidados.

Portanto, pelo exposto, a questão das alianças é fundamental e ela não se pauta apenas pela avaliação objetiva dos programas que serão unidos interinstitucionalmente. A escolha da instituição periférica do Norte-Nordeste pelo Sul-Sudeste pode estar muito mais pautada na presença dos egressos das últimas nas primeiras, do que na produção efetiva da periferia. Neste sentido, o objetivo da política interinstitucional está enviesado de princípio, podendo impossibilitar que instituições, que porventura não atraiam egressos do Sudeste vistos como promissores, dificilmente se beneficiem desse tipo de aliança interinstitucional. E, disfarçadamente, servindo mais a contínua consolidação do Sudeste do que ao desenvolvimento da pesquisa científica na periferia do país. Ou dito de outra forma, a política interinstitucional vai reproduzir as distorções que ela procura sanar, não conseguindo impulsionar alguns programas ao primeiro time da produção científica nacional e, indiretamente, mantendo como eternamente consolidadas as IES do Sudeste em detrimento das demais ${ }^{8}$. Isto rebate noutra

\footnotetext{
${ }^{8}$ Schwartzman (2007), em entrevista ao Jornal da Unicamp, afirma que a tendência mundial dos países é seguir o modelo americano de concentrar os recursos de pesquisa em centros de excelência devendo as demais instituições dedicar-se ao ensino. Ele defende este modelo como uma forma de dar densidade à pesquisa brasileira. Na mesma entrevista o pesquisador chama a atenção para
} 
questão. Até que ponto os projetos serão elaborados levando em conta aquilo que as instituições em processo de fortalecimento consideram importante localmente, ou efetivamente desejam investigar? Se isto não ocorre, como as instituições mais "fracas" conquistarão a autonomia de investigação?

Sem esgotar o rol das questões possíveis de serem levantadas, passemos a outros fatos desta etnografia... Finalmente conseguimos chegar a um acordo sobre quem seria reunido pelo nosso PROCAD: uma grande instituição do Sul-sudeste (nota 7) ${ }^{9}$, a proponente, que se aliaria a um rol de PPG's localizados nas regiões Centro-oeste, Norte e Nordeste, cada um deles com diferentes notas atribuídas pela Capes.

Assim, equipe relativamente vislumbrada, resistências, receios e conjeturas parcialmente controlados, partimos para pensar: que tema de pesquisa poderia ser mote para um projeto de articulação de programas classificados como muito bons e excelentes e programas em formação, que pretendiam se alçar ao Olimpo da pesquisa nacional? Desta feita "a porca deu uma esticada no rabo" e conseguimos encontrar mais rapidamente o tema em questão: seriamos todos reunidos pelos processos da memória, entre o lembrar e o esquecer lutaríamos para que alguns esquecidos pudessem novamente ser lembrados. Aqui me refiro ao investimento de registrar a memória de operários, de camponeses, de povos indígenas ${ }^{10} \ldots$ Significando, simultaneamente, retomar pesquisas anteriores - da década de 1970 - nas quais estas populações tinham sido estudadas, considerando, numa visada comparativa, novos acontecimentos e processos que teriam surgido tentando compreender transformações e continuidades na estrutura social e cultural que as envolviam - no duplo sentido de serem produto e produtores de suas culturas e das sociedades que formavam.

Iniciamos afeitura do projeto, o quepassava por sentarmo-nos regularmente em frente ao computador para compor a muitas mãos nossa sinfonia. Diga-se de passagem, que nem sempre encontrávamos um lugar para nos abrigar, sucessivos

a necessidade de envolvimento das IES de excelência no desenvolvimento de políticas públicas. Voltarei a este ponto mais adiante.

${ }^{9}$ Tendo em vista que uma das regras de uma etnografia é não fornecer pistas que levem a identificação do grupo investigado não posso mencionar a instituição aqui.

${ }^{10} \mathrm{~A}$ escolha dessas populações possibilitava reunir os PPG's, pois os professores que comporiam a equipe do PROCAD já vinham desenvolvendo pesquisas que visavam registrar a história de grupos desse tipo. Dessa forma o projeto tomava corpo (equipe) e consistência (sujeitos, teoria e método). 
disquetes foram gravados - ainda éramos muito "primitivos" em 2005 para ter computadores que gravassem $\mathrm{CD}$ e muito menos possuíamos pen-drive - para tornar possível a continuidade da escrita, passando de um "piano" a outro. Com teclados e afinações mais ou menos palatáveis, ou mais adequadamente, digitalizáveis, fomos dando corpo ao projeto. Mas, além do nomadismo constante, precisávamos nos arranjar, aqui uma metáfora perfeita, sobre o que escrever. Ter muitos compositores, todos com seus estilos, implicou em negociar mui bem o tom, melodia, harmonia e outros detalhes da sinfonia a ser composta. Não faltaram mal-entendidos. Para contornar, só mesmo muita paciência, capacidade de negociar, e vá lá, apesar do tom cristão, muita humildade. Tiro do meu "diário de campo", alguns exemplos:

Um belo dia, após algumas modificações sobre como articular as pesquisas antigas com novos temas a serem investigados, eu e um colega carregamos no tom e foi-se um acorde. Da minha perspectiva, a ligação entre o que tinha sido feito e o que faríamos estava perfeita, semifusas num trinado maravilhoso. Qual o quê! Não compreendêramos (eu e o outro colega) a metade da pauta anterior e dava a impressão de que o já pesquisado tornara-se anacrônico, somente estava ali para servir de justificativa para a escolha do campo, ou nem isso. Deveria ser lembrado como suporte das novas investigações, mas sem trazer para elas nenhuma contribuição para interpretar os novos dados.

Dito de outra maneira, a própria intenção da pesquisa de compreender processos de transformação e continuidade nas relações sociais e nas culturas das populações estudadas, iria por água a baixo. Se não fosse a delicadeza, comedimento e respeito da parte de quem se sentiu incompreendido, a elaboração do projeto teria sido interrompida. Para que pudéssemos novamente voltar à composição precisamos nos afastar do trabalho conjunto durante uns dois ou três dias, distanciamento necessário para aclarar o entendimento, acalmar os ânimos e retomar a empreitada.

Mas não são apenas os encadeamentos das palavras que podem inviabilizar a escrita conjunta, as diferenças de ritmo de trabalho também contam. Outra citação do "diário":

Todo entardecer era a mesma coisa. Estávamos em três na sala e, daí a pouco, um colega iniciava sua circulação, parava atrás da cadeira do computador e desandava a falar: eu não agüento mais/ eu estou muito cansado/ vamos parar por aqui. E voltava a caminhar, a passar a mão na cabeça, a erguer os 
braços... Eu respondia: espere um pouco/ vamos ficar mais/ olha o prazo/ tenha paciêncial já, já acaba/ só mais um pouquinho... e de lá o colega dizia: Ah! Não/deixa assim mesmo/ eles não vão nem perceber/vamos de qualquer jeito/ eu não agüento mais/ e, nesse vai-e-vem, ele continuava, num reclamar sem fim. Até que eu, já cansada e irritada, dizia: pare com isso! E num tom mais brando: por que você não vai para casa descansar? eu só termino este parágrafo e vou... E assim fazíamos... 0 outro colega apenas assistia a tudo calado, na maior paciência. Não que o colega que expunha seu cansaço não estivesse coberto de razão, a tarefa nos deixava extenuados. Mas esta passagem coloca em evidência que as diferenças de ritmo existem, precisando ser contornadas e isto requer acolhida do cansaço do outro, bem como que as admoestações não podem ser levadas ao pé da letra.

Aqui o leitor pode estar se perguntando: então a equipe toda se reduzia a três pessoas? E como podia ser interinstitucional se todos estavam juntos? Alguém veio para o Recife apenas para escrever o projeto?

Bem, vamos esclarecer: o texto composto a seis mãos, ou seja, no seu burilar para articulação de temas de pesquisas em desenvolvimento sob o manto da memória, recebia contribuições constantes por e-mail. Outras pessoas nos davam informes sobre as pesquisas que outros colegas estavam fazendo nas suas IES de origem, destes relatos elaborávamos seus interesses de pesquisa em consonância com o objetivo maior do projeto. Quanto aos outros colegas do PPGA, que não puderam escrever conosco, íamos incorporando suas intenções. Cabe ressaltar que o projeto tanto articulava pesquisas em andamento, como aquelas que seriam realizadas no seu decorrer.

Mas o que pensar a partir daí como uma possível interpretação destes dados "brutos" do campo? Que não se escreve um projeto interinstitucional com investimento de tempo igual entre todos os membros da equipe. É necessário confiar e ser solidário com os colegas para que um projeto venha à luz, e aqui sem teorias altruístas durkheimianas. Se cada um ficar medindo o tempo que investiu e cobrar de todos iguais investimentos, o fracasso da empreitada não precisa ser dado pela Capes, a equipe dá conta de fazer isso antes. Outra questão, e para antropólogos/ cientistas sociais muitos preocupados com autorias e estilos isto pode se anunciar como um tipo de morte. É preciso deixar um pouco de lado estilos rebuscados e mais literários, por um lado, a bem da clareza - linguagem de projeto raramente pode fugir a seco e torturante modo requerido pelos avaliadores; por outro lado, 
a bem da própria possibilidade da composição, nem sempre é possível contemplar todas as características de escrita dos autores. E, por fim, escrever coletivamente requer certo despudor, literalmente a crítica deve ser vista como um favorecimento para que sua idéia seja mantida. Ou se percebe que o mais importante é aclarar os objetivos, consolidar as justificativas, amarrar temas específicos dentro de um conjunto coerente, ou o projeto se transforma num recorta e cola sem revisão. Enfim, um projeto obscuro. Por sua vez, se a vaidade de ver suas idéias e temas em evidência não for controlada, adeus aliança. E, como suposto, a consangüinidade não conta em se tratando de projeto interinstitucional, pois temos que praticar a exogamia prescrita no edital.

Mas o pior mesmo estava por vir. Obviamente o projeto ficou pronto após o terceiro cantar do galo e as simultâneas negações de Pedro ao seu venerado Cristo. E quem disse que o formulário eletrônico, cuidadosamente montado pela Capes para enlouquecer até o próprio Jó, estava preenchido? E quem foi que teve a brilhante idéia de reunir os dados mais preciosos da equipe, em se tratando de burocracia, ou seja, o CPF de todos os membros que já tinham seus nomes definidos? Como o projeto era a mais importante parte da sinfonia, ele havia tomado todos os nossos esforços. Aí "a porca torceu o rabo" e guinchou bem alto. Foi um corre-corre... Para não mais me alongar, deixo que a imaginação de leitor complete o quadro. Como último dado: saímos da UFPE às sete e meia da noite para postar o projeto (ainda tem mais essa, não era envio eletrônico), exatamente meia hora antes de fechar a última agência dos Correios do Recife - informação que obtivemos previamente, pois somos desavisados, mas nem tanto.

Fatigada, levemente esperançada, um pouco convencida sobre nossa capacidade de escrita conjunta, relativamente segura quanto à nossa possibilidade de funcionarmos como equipe e doida para descansar, mas tão ansiosa e com a tela do computador ainda dançando na minha frente, que, naquela noite, a insônia foi certa.

Com este breve relato sobre a elaboração do projeto fica evidente que 0 esforço de colaboração foi fundamental para a sua conclusão. Nesse sentido, parece-me, a despeito das regras draconianas de pontuação instituídas pela Capes, prevaleceu, da parte dos que se envolveram, a disposição cooperativa em detrimento da competição. Deixou-se de lado as pontuações curriculares individuais em favor de um projeto coletivo que poderia trazer benefícios a longo prazo para um conjunto de PPG’s. Sem pretender ares de Madre Tereza de Calcutá, esta disposição 
é que deveria ser fortalecida pela Capes como, por exemplo, atribuir pontuação à confecção de projetos, especialmente os coletivos, quando eles tivessem pareceres favoráveis de agências de fomento, a despeito de serem financiados ou não. Por que somente o resultado da pesquisa conta para pontuar? Será que podemos fazer pesquisa sem elaborar o projeto que the norteia? $\mathrm{E}$, afinal, saber fazer pesquisa não é antes de tudo saber fazer perguntas, mais do que poder dar a resposta, segundo, pelo menos, nossa vã epistemologia? Se a Capes mede produtividade, por que algumas produções contam e outras não? Neste caso, este trabalho que tivemos para elaborar o projeto para o edital PROCAD/2005, foi em vão, nem pontos no currículo, nem dinheiro para levá-lo em frente, mas esta já é outra conversa que trato no item seguinte.

\section{As ViCissitudes da AVALIAÇÃO: CAPES, PONTUAÇÕES E TRABALHOS INVISÍVEIS}

A guisa de palavras finais, pensando sobre as propostas Capes de projetos entre instituições será que valeu a pena? No nosso caso específico, tivemos uma aprovação curiosa, parafraseando o parecer: projeto com mérito, recursos com demérito e ponto!

Por sua vez, os avaliadores não nos deram chances de montar um recurso, pois não fizeram uma única sugestão para redimensionar o projeto. Eles, os avaliadores, simplesmente nos deixaram às cegas, além de já estarmos a ver navios ${ }^{11}$. Julgamos que poderia ter sido seu formato, ou seja, o número de instituições, de pessoas envolvidas e suas localizações (Nordeste, Centro-Oeste, Norte e Sul-Sudeste, implicam um investimento em passagens, diárias e bolsas que elevaram o montante de recursos a limite permitido). Mas também poderiam ter sido as atividades propostas. Entretanto, sem uma indicação no parecer final consideramos que qualquer recurso falharia nos seus objetivos.

Cabe assim perguntar: o que se pretende em projetos interinstitucionais? É, de fato, alargar a possibilidade de articulação entre as distintas regiões? Se for assim, como se justifica desmerecer um projeto pela dimensão dos recursos, inevitavelmente altos, quando se pretende articular regiões longínquas? Por sua

\footnotetext{
${ }^{11}$ Esta, ao que parece, não é uma questão específica que nós enfrentamos com esta experiência. Em relação ao CNPq a situação se repete, segundo exemplo citado por Carpinteiro (2009), um parecer ad-hoc desqualificou uma proposta com a justificativa do volume de recursos solicitados, sem ao mesmo mencionar a qualidade do projeto.
} 
vez, como não foi possível saber pela página da Capes o montante de dinheiro para os outros projetos, como avaliar se nosso problema foi mesmo de recursos? Junte-se a isso o fato de que foi escolhido um outro projeto dentro da instituição consolidada que encabeçava nossa equipe, sendo essa a suposição que elegemos como razão de não termos tido aprovação. Entretanto, para a área de exatas houve PPG agraciado com mais de um projeto...

Deslocando-se um pouco destas considerações relativas ao nosso próprio projeto para pensar sobre este tipo de política como um todo, cabe perguntar: por que é possível que duas instituições consolidadas se aliem em projetos deste tipo e nunca isto possa acontecer entre instituições em formação? Será que instituições em processo de formação não podem aprender com suas experiências mútuas? A Capes ao agir dessa maneira não estaria, implicitamente, beneficiando as consolidadas, e também repetindo a histórica desigualdade centro-periferia? Ao que parece as instituições consolidadas estão sempre com recursos duplos: ao se aliarem entre si e ao se aliarem com seus "outros". Daí, seus laboratórios, bibliotecas e outros equipamentos podem sempre ser atualizados e estar em crescimento.

Da mesma forma, seus integrantes têm, provavelmente, mais chances de circulação nacional e internacional, aumentando seu reconhecimento e prestígio. Se é preciso circular para se consolidar, os integrantes de PPG's em formação terão como resultado ficarem plantados no mesmo lugar de sempre, sua periferia. Este procedimento também elimina uma possibilidade cognitiva humana: que "crianças" possam aprender entre si. Outras críticas poderiam ser aduzidas, entretanto, quem sou eu para dizer como podem ou não viajar as instituições? Fica para os "deuses" explicarem o mistério de como os "sólidos" voam, navegam ou correm...

Anteriormente, mencionei como os critérios avaliativos da Capes tornam invisíveis trabalhos cruciais que realizamos para produzir resultados publicáveis, como não pontuar projetos de pesquisa aprovados por nossos pares. De certa forma, como era ainda recente no programa, pensei que poderia ser apenas isso.

Continuei com outras atividades realizadas em equipe. Uma delas, a mais recente, é a coordenação de um curso a distância para professores do ensino básico da rede pública (estadual e municipal) sobre conteúdos transversais nas escolas. 0 curso chama-se Gênero e Diversidade na Escola (GDE) ${ }^{12}$, financiado pela Secretaria

${ }^{12}$ Compõem a equipe do GDE: Marion Quadros (PPGA e Núcleo de Formação Docente - Centro Acadêmico do Agreste/UFPE), Luis Felipe Rios do Nascimento (PPGA e Mestrado de Psicologia 
Especial de Políticas para as Mulheres da Presidência da República (SPM), pelo MEC (Secretaria de Educação Continuada, Alfabetização e Diversidade - SECAD; e, Secretaria de Educação a Distância - SEED), pelo FNDE e desenvolvido nos pólos da Universidade Aberta do Brasil (UAB), atualmente órgão abrigado na Capes. Este curso é uma das ações da política do MEC de melhoria do ensino básico mediante o envolvimento das IES, especialmente as públicas.

É uma atividade de extensão, mas a seleção, por edital, foi feita como uma ação do Núcleo de Pesquisa Família, Gênero e Sexualidade (FAGES) do PPGA, em parceria com o Grupo de Pesquisa Gênero, Educação e Inclusão (GEIN) do Núcleo de Formação Docente. Sabemos que ganhamos o edital porque o FAGES é reconhecido nacionalmente. Sabemos também que esta seleção considerou nosso envolvimento numa pós-graduação. Finalmente, sabemos que decorreu da experiência de pesquisa e ensino na temática de gênero. Mas, para nossa surpresa, na última visita dos avaliadores da Capes fomos informados que sua pontuação é muito baixa, que somente contaria pontos relevantes para o PPGA (que teve sua nota rebaixada no último triênio) se resultasse em publicação em periódicos.

Curiosamente, uma das instituições envolvidas na implementação do GDE está sediada na Capes, por sua vez o curso é uma ação estratégica dentro de uma política nacional de educação do MEC. Cabe perguntar, os avaliadores da Capes desconhecem sua própria instituição? Ou eles não consideram importante o envolvimento dos PPG's nas políticas do MEC? Ou seriam ambas as razões? Por que não é uma atividade de produção de conhecimento se fomos selecionados em decorrência de sermos doutores dentro de um PPG's especialista na temática do curso?

Esta é a minha mais recente perplexidade: a desconexão entre os critérios de pontuação da Capes e as políticas educacionais do país. Se, por um lado, conta pontos nas avaliações, embora muito pouco, a inserção social dos PPG's, por outro, conta menos ainda para avaliação dos docentes individualmente, a participação em políticas sociais do MEC ${ }^{13}$. Fico me perguntando por que somente "produzo"

Social), Jaileila de Araújo Menezes-Santos (Mestrado de Psicologia Social) Karla Galvão Adrião (Mestrado de Psicologia Social). 0 projeto de Extensão é interdepartamental entre Departamento de Ciências Sociais e Núcleo de Formação Docente.

${ }^{13}$ Cito a seguir afirmação de Schwartzman (2007): “Todos os países estão tratando de concentrar os recursos nas instituições de ponta, além de vinculá-los fortemente ao setor empresarial e a agências governamentais responsáveis pelas políticas públicas nas diversas áreas, que dependem de conhecimentos científicos e técnicos". Por esta afirmativa o projeto não pontuado pela Capes 
conhecimento quando publico e não estou produzindo se realizo um trabalho "técnico". Quantas doutoras há dentro de mim? Qual delas é produtiva e qual delas está brincando que sabe? Quantas devo ser para ter pontuação? Isto me parece com o valor atribuído ao trabalho doméstico das mulheres, por mais que seja metrificado monetariamente e consuma tempo continua sendo invisível.

Por fim, ao ler a história da fundação do Departamento de Antropologia de Chicago me chamou a atenção que alguns nomes citados eu sabia exatamente de quem se tratava como, por exemplo, Sapir, porém jamais ouvira o nome de FayCooper Cole (STOCKING Jr. 2004). Mas este homem, cujo nome é pouco conhecido internacionalmente, foi fundamental para fundar o Departamento. Conseguiu recursos para as pesquisas e edificações, criou novas vagas e contratações, reuniu pessoas que deram renome à instituição, também produziu pesquisas, mas que são citadas rapidamente por Stocking Jr.

Sapir ficou para a posteridade, mas sem Cole, que deu sustentação ao departamento, isto não ocorreria. Resta saber se Cole poderia ter feito o que fez se houvesse, naquele momento, políticas de avaliação tipo Capes as quais balizam a distribuição de recursos para pesquisa. Quero com isso destacar que um departamento se faz com o trabalho dos que se tornam renomados, mediante publicações, mas se faz com o trabalho administrativo daqueles que não deixam seu nome no solo da fama. Até aí não há novidade.

Usando um adjetivo forte, é estarrecedor que os avaliadores da Capes insistam em negar isso e continuem enfatizando a pontuação de produção bibliográfica $^{14}$, apagando o esforço administrativo necessário para montar um departamento. Bem como, desconsiderem a produção técnica, que decorre do

somente seria desenvolvido em uma instituição de ponta, resta saber como poderemos chegar lá se forem mantidos os critérios atuais de avaliação. Não posso deixar de notar que um dos problemas das IES para Schwartzman decorre da situação do ensino médio brasileiro, sendo uma das soluções que ele aponta para este problema o investimento na formação de professores. Deixo ao leitor a reflexão sobre este paradoxo em que nos encontramos.

${ }^{14}$ Produção, em alguns casos, bastante duvidosa. Rodrigues (2007) chama a atenção para a maquiagem de currículos mediante o parcelamento de artigos, bem como põe em suspeição a qualidade dos resultados pelo curto espaço de tempo para conclusão das pesquisas, evidenciado no volume anual das publicações encontrado em alguns currículos. Fonseca (1998) desconfiava que um dos resultados da quantificação da Capes poderia ser diminuir a qualidade das publicações e sua criatividade, pela inexistência de tempo para amadurecer os resultados. Coroando tudo isso a diminuição da cooperação entre os pares. 
reconhecimento da nossa formação de doutores e da nossa inserção em PPG's. Ao insistir nessa cegueira a Capes pode, junto com a água do banho, jogar esses mesmos PPG's, os alvos de suas avaliações.

Se podemos nos balizar pelos acontecimentos passados, que se constituem em experiência (THOMPSON, 1981), está mais do que na hora da Capes repensar como pontua o que realizamos nos PPG's. Uma política de avaliação de instituições, como são os PPG's, não pode apenas se fixar no renome oriundo dos que publicam. Deve considerar todas as atividades necessárias para que a instituição exista. Produção acadêmica se compõe de um conjunto de ações e não apenas de publicações em periódicos. E estas outras atividades devem também ser pontuadas quando se avalia o currículo para financiamento de projetos, pois se passo um tempo trabalhando na administração certamente terei que diminuir o investimento nas pesquisas, a bem da minha sanidade e da qualidade dos resultados.

E, para não lhes brindar com um fim melancólico, uma palavra de ordem, ainda que obscura, talvez seja interessante: que viva o mérito, mas nem tanto, que de vez em quando ele possa ser substituído pela justiça!

\section{REFERÊNCIAS}

ALBERNAZ, Lady Selma F. Etnografia Sucinta de um Projeto Científico ou das Lições de Política Inter-Institucional. In: NORONHA, Nelson Matos de; ATHIAS, Renato. (Org.). Ciências e Saberes na Amazônia - Indivíduos, Coletividades, Gênero e Etnias. 1 ed. Recife: EDUFPE, 2008. p. 211-224

ANDRADE, Maristela de Paula. Estratégias para contornar as classificações oficiais, pesquisar e formar na "periferia". In: NORONHA, Nelson Matos de; ATHIAS, Renato. (Org.). Ciências e Saberes na Amazônia - Indivíduos, Coletividades, Gênero e Etnias. 1 ed. Recife: EDUFPE, 2008. p. 187-195.

CARPINTEIRO, Otávio A. S. Bolsa de Produtividade: Qual o melhor corredor - 0 que corre 100 metros em 10 segundos ou o que corre em 20 segundos? Disponível em: http://www.jornaldaciencia.org.br/Detalhe.jsp?id=54272. Visitado em 23/03/2009

. A quem se dirige o Edital Universal 2008? Disponível em: http://www. 
jornaldaciencia.org.br/Detalhe.jsp?id=57672. Visitado em 23/03/2009.

CAVALCANTI, Josefa Salete. Desenvolvimento e políticas de pesquisa e formação. In: NORONHA, Nelson Matos de; ATHIAS, Renato. (Org.). Ciências e Saberes na Amazônia - Indivíduos, Coletividades, Gênero e Etnias. 1 ed. Recife: EDUFPE, 2008. p. 197-209.

FONSECA, Cláudia. Avaliação dos programas de pós-graduação: do ponto de vista de um nativo. Horizontes Antropológicos, ano 4, n. 8, junho de 1998. p. 182-198. NORONHA, Nelson Matos de; ATHIAS, Renato. Introdução. In: NORONHA, Nelson Matos de; ATHIAS, Renato. (Org.). Ciências e Saberes na Amazônia - Indivíduos, Coletividades, Gênero e Etnias. 1 ed. Recife: EDUFPE, 2008. p. 7-12.

RODRIGUES, Luiz Oswaldo Carneiro. Publicar mais, ou melhor? 0 tamanduá olímpico. Revista Brasileira de Ciências do Esporte. 29 (1), 2007. p. 35-48.

SCHWARTZMAN, Simon. A universidade segundo Schwartzman. Entrevista. Jornal da Unicamp. Edição 356, 23 de abril a 6 de Maio de 2007. Disponível em: http:// www.unicamp.br/unicamp/unicamp_hoje/ju/abril2007/ju356pag05.html. Visitado em 23/03/2009.

STOCKING Jr, George W. Antropologia em Chicago: a fundação de um departamento independente - 1923-1929. In: Peixoto, Pontes e Schwarcz (orgs.). Antropologias, Histórias, Experiências. Belo Horizonte: Editora UFMG, 2004. p. 15-59.

THOMPSON, Edward Palmer. 0 termo ausente: experiência. In: A miséria da teoria: ou um planetário de erros. Rio de janeiro: Zahar Editores, 1981. p. 180-201. VIEIRA, Wilson José. A casta dos superbacharéis. Correio Braziliense. Opinião. 07/02/2009. 